\title{
LANDSLIDE RUNOUT DISTANCE PREDICTION BASED ON MECHANISM AND CAUSE OF SOIL OR ROCK MASS MOVEMENT
}

\author{
Muhammad Qarinur \\ Civil Engineering Department, College of Technique Harapan, Medan, INDONESIA \\ muhammad.qarinur@mail.ugm.ac.id
}

\begin{abstract}
Landslide often occurs in tropical hills area, such as Indonesia. Research on landslide hazard evaluation is necessary to decrease the impact in affected and surrounding areas. Empirical-statistical methods can be used to predict landslide run out distance in an effort to avoid the danger of landslide occurrences. This study aims to determine the correlation between landslide run out distance against high, slope, and volume based on mechanisms and causes of soil or rock mass movement. Data mainly from 106 landslides in Indonesia has been analyzed to search for possible correlations and empirical correlations, there are 34 rotational slides, 54 translational slides, 8 debris flows, and 10 rock falls. Analysis begins by studying the characteristics of the data (explanatory data analysis) and then analyzed by using empirical methods such as geomorphological assessment and geometrical approaches. Then the data is processed by simple linear regression and multiple linear regression method using the $\mathrm{R}$ software. The results obtained from the analysis of the general empirical equation form of the correlation between height $(H)$ and run out distance $(L)$ is $1.066 H^{1.093}$, respectively. This results indicate the higher altitude slopes, the greater distance will happen. The results of the analysis correlation between height and run out distance for the type of mass movements for rotational is $L=1.346+1.788 H$, translational is $L=-3.88+1.578 H$, debris flow is $L=0.682 H^{1.29}$, and rock fall is $L=2.223 H^{0.897}$. This result shows debris flows landslide run out distance is greater than rotational, translational and rock fall. The results of the analysis correlation between height and run out distance of the trigger due to the rain is $L=1.267 H^{1.027}$, and by an earthquake is $L=0.574 H^{1.38}$. This results show run out distance caused by an earthquake is larger than caused by rain. The correlation between the run out distance and volume $(V)$ yields empirical equation which is $V=0.772 L^{2.108}$. This results indicate that greater run out distance is affected by the growing volume of mass movement. The results of the analysis correlation between height and slope $(\theta)$ to run out distance is $L=1.448 H^{1.062} \tan \theta^{-0,482}$. This results indicate that slope has a significant impact on the value of landslide run out distance.
\end{abstract}

Keywords: landslide run out prediction, explanatory data analysis, empirical method, regression analysis

\section{INTRODUCTION}

Landslide often occurs in tropical hills area such as Indonesia. Research on landslide hazard evaluation is necessary to decrease the impact in affected and surrounding areas. Because of that, predictive methods and measures required to reduce the impact.

Empirical-statistical method will be useful to predict landslide run out prediction and the coverage impact area of debris flow and another mass movements (Rickenmann, 1999). Interpretation on the satellite imagery, field survey and field measurement as well as empirical analyses were carried out to support the investigation and prediction of potential impacts of landslides (Karnawati \& Fathani, 2007). Additionally, this method can provide information on the rheological properties used for mathematical modelling of mass movements. (Devoli, et al., 2009).

This research describes the physical characteristics of landslides in Indonesia which is represented into empirical correlations between run out distance, height of slope, slope angle, and landslide volume. This study will provide an empirical formula that can be used in the evaluation of landslide hazard in Indonesia and part of a broader research effort to improve the knowledge about the landslide in Indonesia, especially those which is contained in the draft of academic master plan on landslide disaster risk reduction as one part of the national plan for disaster management composed for natural disasters preparedness in Indonesia (Fathani \& Wilopo, 2013).

\section{LANDSLIDE RUN OUT PREDICTION}

Early work of landslide run out prediction was conducted by Heim (1932) and Terzaghi (1950) recited in Hungr, et al., (2005). It is aimed to understand characteristics of landslide in the past event in order to avoid losses and fatalities due to foregoing landslides. Prediction of landslide run out distance can be either measured directly, or by conducting laboratory experiment and mathematical modelling. 
McKinnon (2010) developed different types of mathematical models using different assumptions of the landslide phenomena. These different assumptions lead to different limitations in the applicability of the model. There are several mathematic models which are used for analyzing landslide run out distance, i.e. statistical models and dynamic models.

Proper statistical models should only be applied in conditions similar to the events used in the statistical (Rickenmann, 2005). Statistical models are very easy and practice to use, with very low computational demand because all the statistical analysis are done in advance and do not require additional adjustment for new target cases. (McKinnon, 2010). Methods for predicting landslide run out in this study can be group into two methods, i.e. geomorphological-based and geometrical approaches. Field work and image satellite interpretation are the main sources of the geomorphological analysis for determining the run out distance of landslides (Hungr, et al., 2005). The assessment of both past and future landslide deposits is the basis for defining future run out distances.

The parameters considered in geometry approach can be seen in Figure 1. The difference between the highest elevation of the source area (crown) and the initial bending towards the direction of the slope gentler is called height of slope $(H)$. Run out distance $(L)$ is defined as the horizontal projection of the line connecting the upper part of the landslide source area to the farthest edge of the movement of the landslide deposit and $(\theta)$ is slope angle before failure.

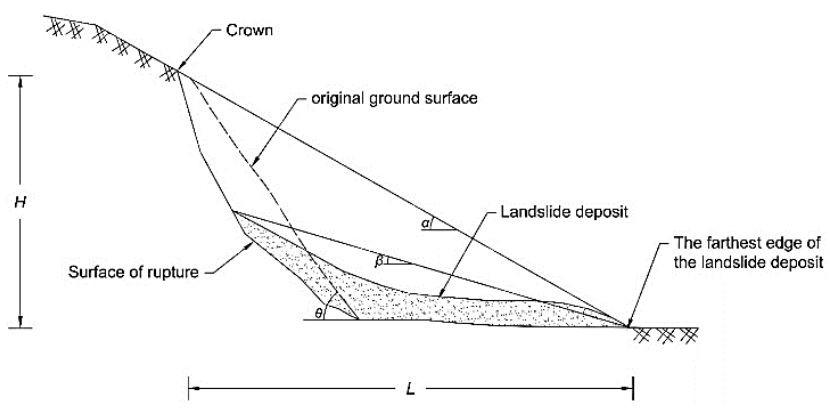

Figure 1. Geometrical variables: height of slope $(H)$, run out distance $(L)$, reach angle $(\alpha)$, shadow angle $(\beta)$, slope angle $(\theta)$ (Hungr, et al., 2005).

\section{EMPIRICAL METHOD OF LANDSLIDE PREDICTION}

Location of research spread over several islands in Indonesia (Figure 2) which has a number of large landslide events, such as in Sumatera, Java, Bali, Sulawesi, Nusa Tenggara and Maluku Island.

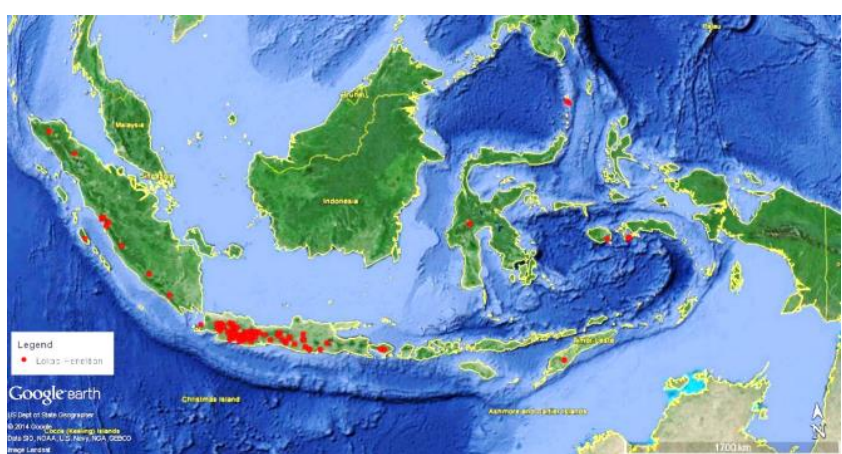

Figure 2. Location of research.

Landslide data processing were obtained from a brief report on Indonesian soil movement events collected from 2007 to 2013 by the Center for Volcanology and Geological Hazard Mitigation (PVMBG, 2013), internet, journals, newspapers, and field surveys. Field surveys were carried out in the form of slope geometry measurements by using a distance measuring device (Range finder/Hypsometer) and the landslide volume can be estimated by the formula (Cruden \& Varnes, 1996):

$V=\frac{1}{6} \pi\left(D_{r} \cdot W_{r} \cdot L_{r}\right)$

where $V$ is volume of materials generated from the landslides $\left(\mathrm{m}^{3}\right), D_{r}$ is the maximum depth of surface rupture (meters), $W_{r}$ is the maximum width between the flanks of the landslide (meters) and $L_{r}$ is the minimum distance from toe of surface of rupture to crown (meters). The data will assist in concluding the cause of the incident, the location, duration and impact of landslides.

Empirical equation of landslide run out distance derived from statistical analysis using the $\mathrm{R}$ software by considering run out distance $(L)$, height slope $(H)$, slope angle $(\theta)$, and landslide volume $(V)$. Results of statistical equations obtained from equation will be evaluated/validated with the circumstances on the landslide area.

\section{RESULTS AND DISCUSSIONS}

\subsection{Landslide Data Analysis}

Preliminary analysis in analyzing the data is to study the characteristics of the data (Exploratory Data Analysis - EDA). Landslide run out distance of each type of soil or rock mass movement is shown graphically in the Boxplot chart and histogram distribution. The results of data processing can be seen in Figure 2(a). All of outlier data are beyond the range of run out distance which exceeds $200 \mathrm{~m}$, except for the case of debris flow, run out distance is more than 500 
m. Figure 2(b) shows the frequency of landslide run out distance based on the type of mass movement. This graph indicates that the characteristic landslide run out distance was dominated by such distance less than 200 $\mathrm{m}$ from the landslide area.

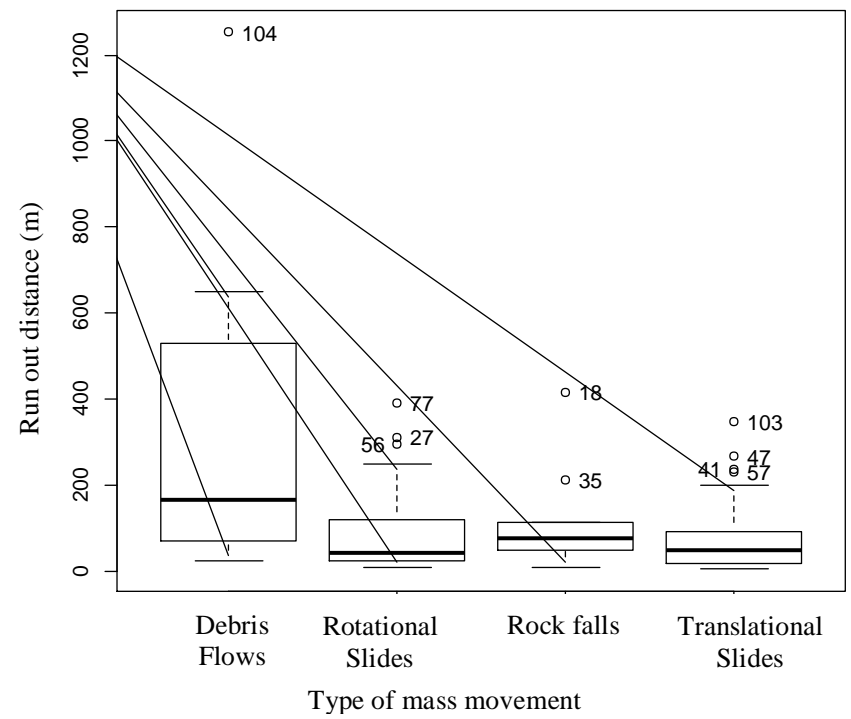

(a)

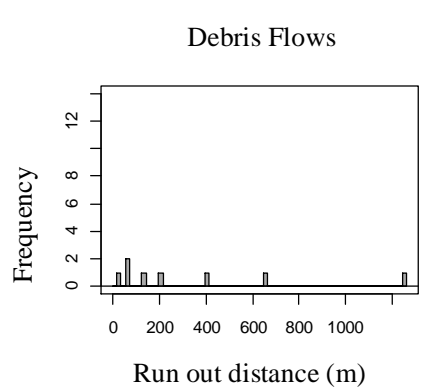

Rock falls
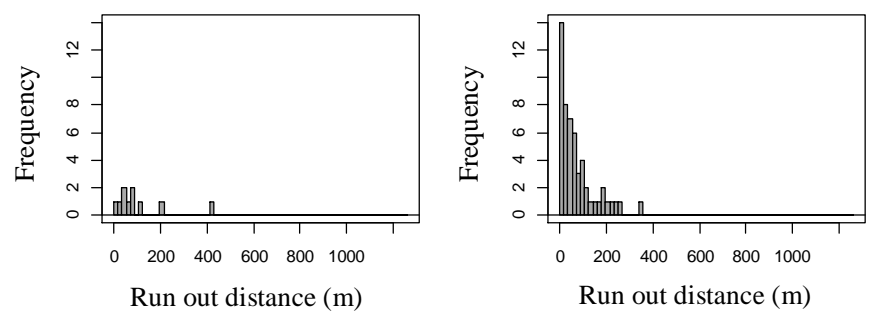

(b)

Figure 3. (a) Boxplot of run out distance data $(L)$ based on the type of mass movement; (b). Histogram of run out distance data $(L)$ based on the type of mass movement.

\subsection{Correlation between Height of Slope and Run out Distance}

The correlation between the height of slope and the run out distance is obtained by plotting the data of height of slope $(\mathrm{H})$ and the landslide run out distance $(\mathrm{L})$ into scatter plot (Figure 4). Linear regression represents the correlation between the height of slope and the run out distance. The correlation can be obtained from the following expression:

$L=1.066 H^{1.093}$

where $L$ is the run out distance (meters) and $H$ is the height of slope (meters). The coefficient of determination is 0.79 . This equation can be used only at the height of slope interval a minimum of $4 \mathrm{~m}$ and a maximum of $220 \mathrm{~m}$. To reduce the errors obtained from the predicted value, then maximum and minimum limits should be follow Equation (3) and Equation (4) as below:

$$
\begin{aligned}
& L_{\text {max }}=3.138 H^{1.093} \\
& L_{\text {min }}=0.364 H^{1.093}
\end{aligned}
$$

where $L_{\max }$ is the maximum run out distance $(\mathrm{m})$ and $L_{\min }$ is the minimum run out distance (m).

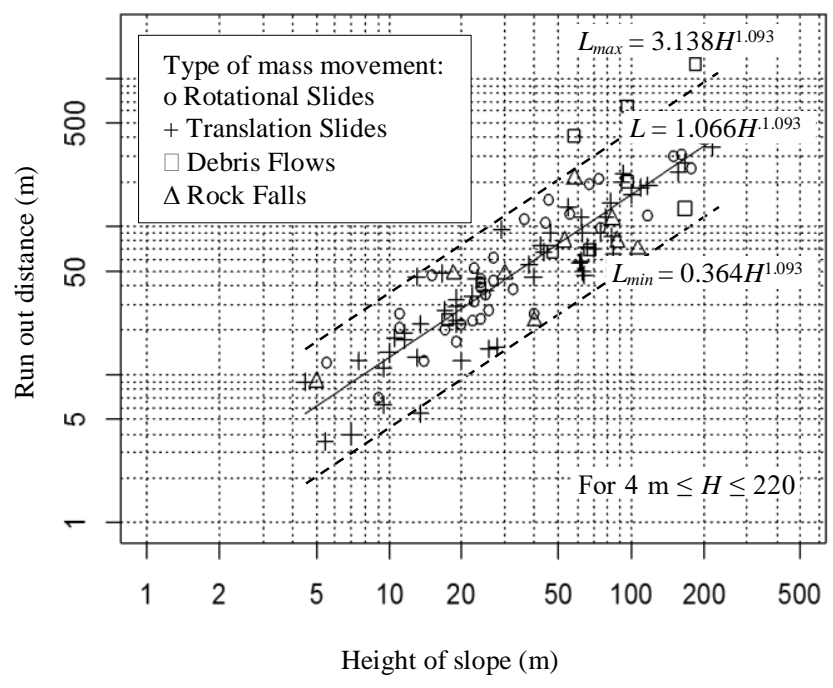

Figure 4. Correlation between height of slope and run out distance.

4.3 Correlation between Height of Slope and the Run out Distance for the Mechanisms

Results of statistical analysis of the correlation between the height of slope and the run out distance for the type of rotational slides are as follows:

$L=1.346+1.788 H$

$L_{\max }=77.055+1.788 H$

$L_{\text {min }}=-74.362+1.788 H$

The coefficient of determination $\left(R^{2}\right)$ is 0.86 . Figure 5 (a) shows linear correlation between the height of slope and the run out distance. It means that for the case of rotational slides, landslide run out distance increases 
with the increase of slope height. These equations can be used only in the slope height range of $5 \mathrm{~m}$ and 200 $\mathrm{m}$

The results of statistical analysis of the correlation between the height of slope and the run out distance for the type of translational slides can be seen as follows:

$L=-3.88+1.578 H$

$L_{\max }=51.317+1.578 H$

$L_{\min }=-59.075+1.578 H$

The coefficient of determination $\left(R^{2}\right)$ is 0.87 . Figure 5 (b) shows the plot of the results of linear regression analysis. Landslide run out distance will increase with increase of slope height. These equations can be used only between $4 \mathrm{~m}$ and $220 \mathrm{~m}$.

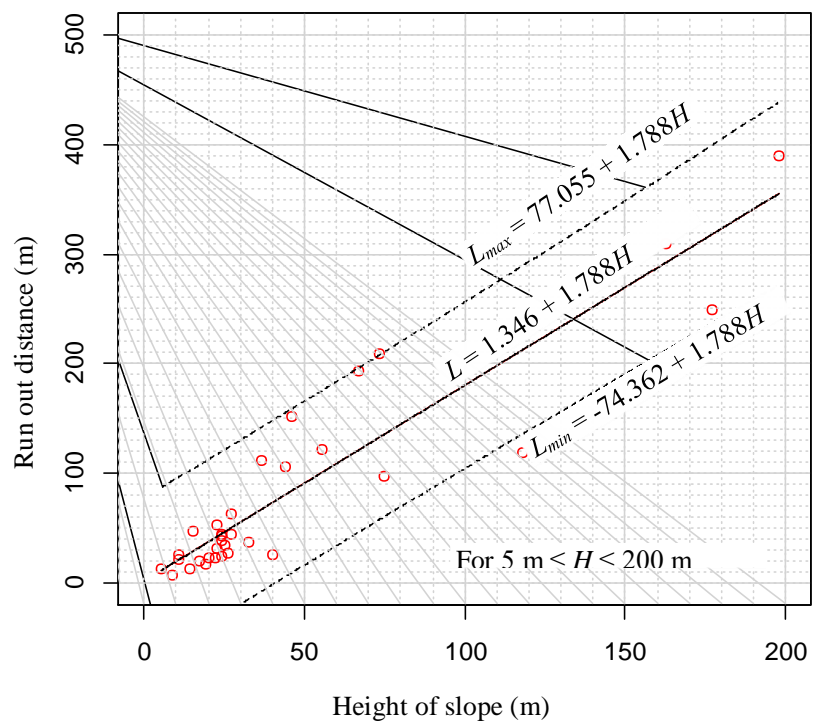

(a)

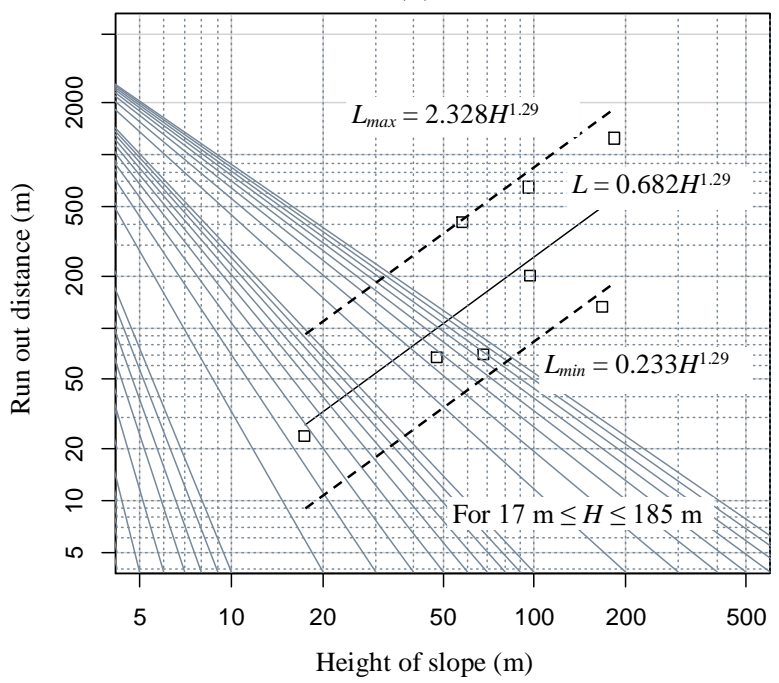

(c)
The results of statistical analysis of the correlation between the height of slope and the run out distance for the type of debris flows can be seen as follows:

$L=0.682 H^{1.29}$

$L_{\max }=2.328 H^{1.29}$

$L_{\min }=0.233 H^{1.29}$

The coefficient of determination $\left(R^{2}\right)$ is 0.54 . Figure $5(\mathrm{c})$ shows the plot of the results of linear regression analysis. Correlation between the height of slope and the run out distance for the debris flows be seen that the landslide run out distance will increase with the increase of slope height. These equations can be used only at intervals of $17 \mathrm{~m}$ and $185 \mathrm{~m}$.

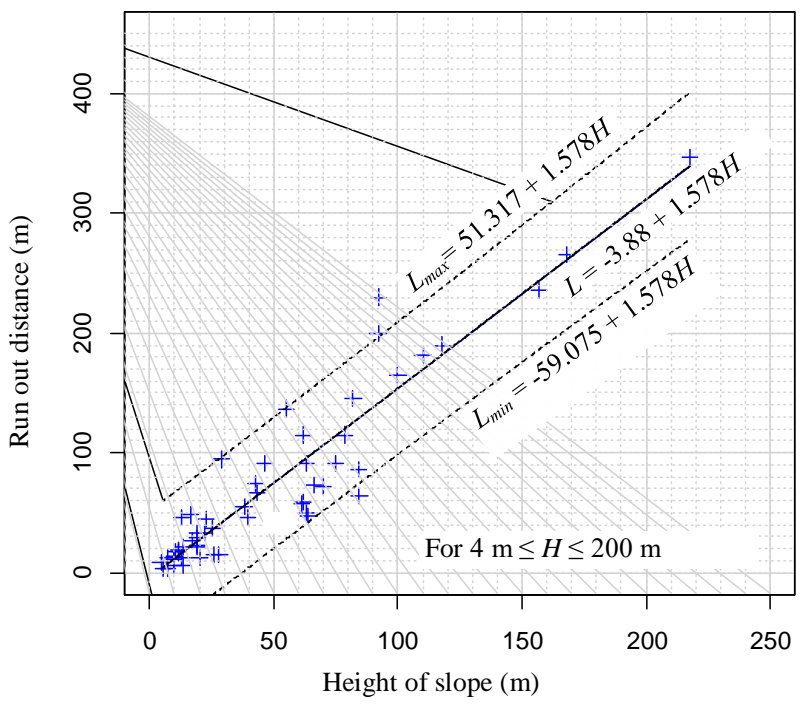

(b)

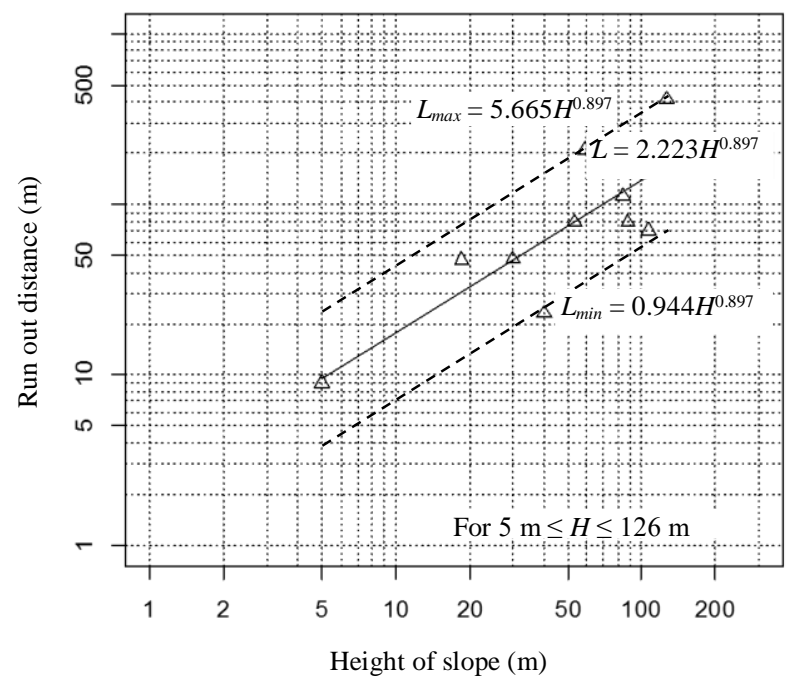

(d)

Figure 5. Correlation between the height of slope and the run out distance based on mechanism of mass movements: (a). rotational slides; (b). translational slides; (c). debris flows; (d). rock falls. 
The result of statistical analysis represents correlation between the height of slope and the run out distance for the type of rock falls are as follows:

$L=2.223 H^{0.897}$

$L_{\max }=5.665 H^{0.897}$

$L_{\min }=0.944 H^{0.897}$

The coefficient of determination $\left(R^{2}\right)$ is 0.66 . Figure 5 (d) depicts linear correlation between the height of slope and the run out distance for the rock falls case can be seen that the landslide run out distance will increase with increasing the height of slope. These equations should be in the range of $5 \mathrm{~m}$ and 126 . From the overall results, it can be concluded that the landslide run out distance of debris flows is greater than rotational slides, translational slides and rock falls.

\subsection{The Landslide Run out Distance Based on the} Cause of Mass Movement

The results of statistical analysis of the correlation between the height of slope and the run out distance cause of rainfall can be seen as follows:

$L=1.267 H^{1.027}$

$L_{\max }=3.378 H^{1.027}$

$L_{\min }=0.478 H^{1.027}$

The coefficient of determination $\left(R^{2}\right)$ is 0.80 . Correlation between the height of slope and the run out distance cause of rainfall can be seen at Figure 6(a). Equations (17), Equation (18), and Equation (19) can be used only between $4 \mathrm{~m}$ and $220 \mathrm{~m}$ of slope height.

The results of statistical analysis of the correlation between the height of slope and the run out distance due to earthquake are as follows:

$L=0.574 H^{1.38}$

$L_{\max }=1.52 H^{1.38}$

$L_{\min }=0.233 H^{1.38}$

The coefficient of determination $\left(R^{2}\right)$ is 0.81 . Correlation between the height of slope and the run out distance due to earthquake can be seen at Figure 6(b) be used only at intervals of height of slope $(H)$ a minimum of $10 \mathrm{~m}$ and a maximum of $185 \mathrm{~m}$.

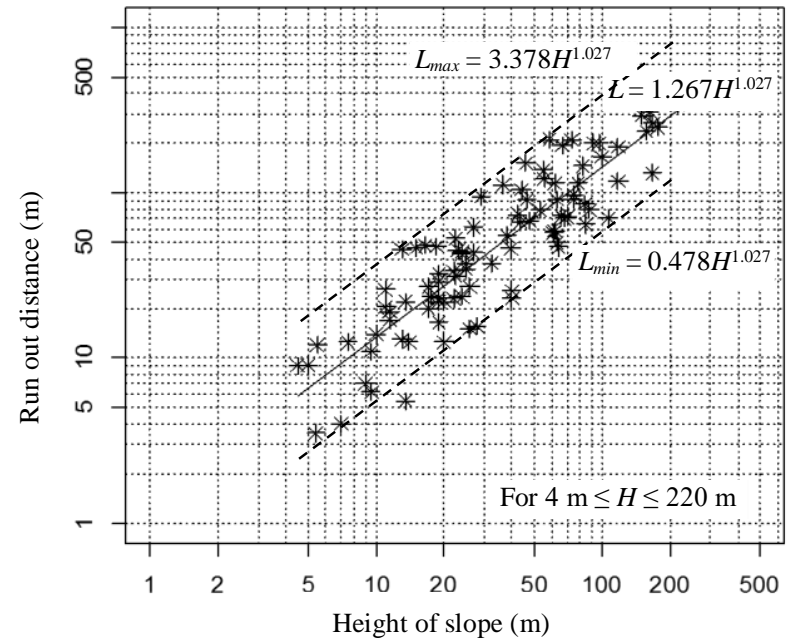

(a)

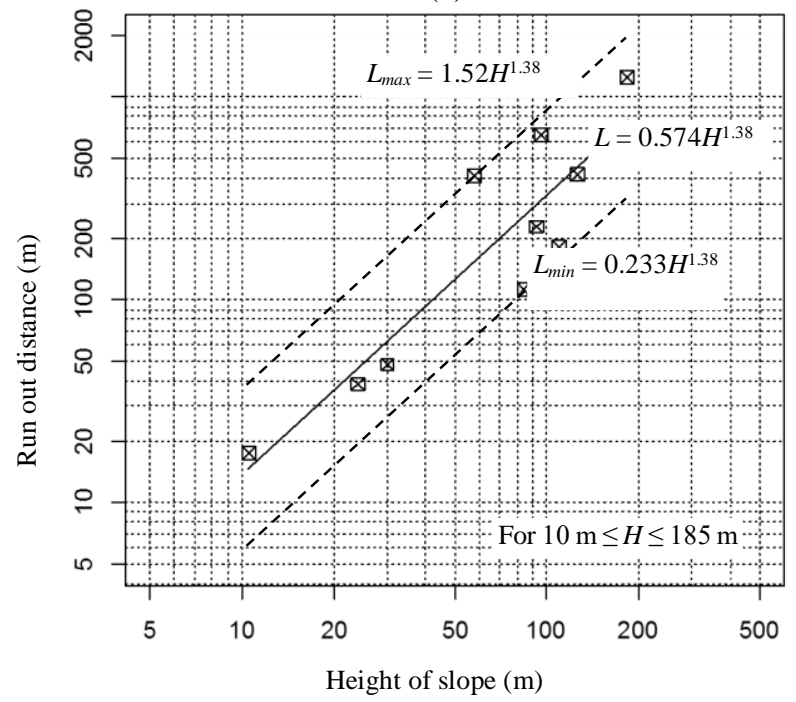

(b)

Figure 6. Correlation between height of slope and run out distance based on cause of mass movements: (a) Rainfall, (b) Earthquake.

4.5 Correlation between the Run out Distance and the Landslide Volume

The results of statistical analysis of the correlation between the run out distance and the landslide volume can be seen as follows:

$V=0.772 L^{2.108}$

$V_{\max }=9.88 L^{2.108}$

$V_{\min }=0.06 L^{2.108}$

where $V$ is landslide volume $\left(\mathrm{m}^{3}\right), V_{\max }$ is maximum of landslide volume $\left(\mathrm{m}^{3}\right)$ and $V_{\min }$ is minimum of landslide volume $\left(\mathrm{m}^{3}\right)$. The coefficient of determination $\left(R^{2}\right)$ is 0.79 . Plotting the results of linear regression analysis is performed and shown in Figure 7. Figure shows that the landslide run out distance will increase with increasing 
the landslide volume. These equations can be used only at intervals of run out distance (L) a minimum of $3 \mathrm{~m}$ and a maximum of $416 \mathrm{~m}(3 \mathrm{~m} \leq \mathrm{L} \leq 416 \mathrm{~m})$.

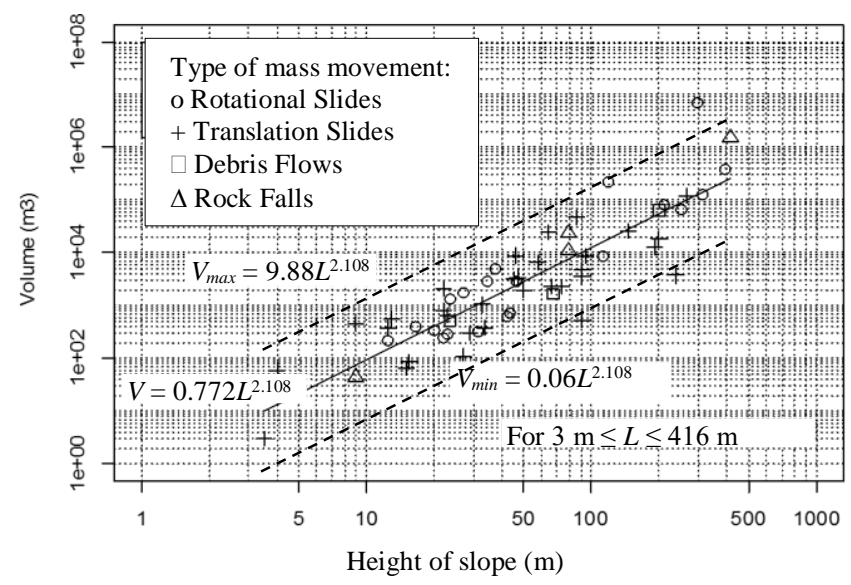

Figure 7. Correlation between run out distance and landslide volume

4.6 Correlation between Height of Slope and Slope Angle against Run out Distance

Geometrical parameters on slope such as height of slope $(\mathrm{H})$ and slope angle $(\theta)$ is used to predict landslide run out distance that may occur. The data are processed using multiple linear regression method because there are two independent variables used in the analysis. The results of multiple linear regression analysis can be seen as follows:

$L=1.448 H^{1.062} \tan \theta^{-0.482}$

The coefficient of determination (R2) is 0.85 . Equation (26) is more appropriate to be applied in predicting the landslide run out distance compared to those using only the parameters in the analysis of height of slope (see Equation 2). It can be seen from the increase of the determination coefficient yielded from Equation (26) is 0.85 , while coefficient of determination yielded from Equation (2) is 0.79 .

\section{CONCLUSIONS}

The height of slope has a linear correlation to the landslide run out distance away. Run out distance will increase with increasing the height of slope. Debris flows run out distance is greater than rotational slides, translational slides and rock falls. The run out distance caused by the earthquake will be relatively similar to that is caused by rainfall when the state of the soil or rock in natural state (not affected by the rain), but it will be different and result much greater distance when the earthquake which occurs at the landslide area has been experiencing rainfall.
The use of an empirical equation of the correlation between height and slope angle is more effective to use, because the original slope angle has a significant influence on the magnitude of landslide run out distance.

Further research is needed to develop run out distance modeling in the laboratory in order to obtain a comparison between laboratory models against numerical and empirical models that already exist. Another research needed to analysis another type of soil or rock mass movements and run out distance analysis based on type of soil or rock slope composing. It should be an analysis of the coverage impact area.

\section{REFERENCES}

Cruden, D. M. \& Varnes, D. J., 1996. Landslide Types and Process: Landslide Investigation and Mitigation. Washington: National Academy Press.

Devoli, G., Blasio, F. V. D., Elverhøi, A. \& Høeg, K., 2009. Statistical Analysis of Landslide Events in Central America and their Run-out Distance. Geotech Geol Eng, Volume 27, p. 23-42.

Fathani, T. F. \& Wilopo, W., 2013. Naskah Akademik Master Plan Bencana Tanah Longsor [Academic Paper for Mastr Plan of Landslide Hazard]. Mataram.

Hungr, O., Corominas, J. \& Eberhardt, E., 2005. State of the Art Paper \#4, Estimating landslide motion mechanism, travel distance and velocity. in Landslide Risk Management. London, Taylor and Francis Group.

Karnawati, D. \& Fathani, T. F., 2007. Mechanism of Earthquake Induced Landslides in Yogyakarta Province, Indonesia. EWS Project.

McKinnon, M., 2010. Landslide Runout Statistical Analysis of Physical Characteristics and Model Parameters, Vancouver: The University Of British Columbia.

\section{PVMBG, 2013. Laporan singkat pemeriksaan} gerakan tanah tahun 2008-2013 [Short Assesment on soil movement in 2008-2013]. Bandung: PVMBG.

Rickenmann, D., 1999. Empirical relationships for debris flows. Nat Hazards, Volume 19, p. 47-77. 
Rickenmann, D., 2005. Runout prediction models. In:

Debris-flow Hazards and Related Phenomena.

Springer Berlin Heidelberg, p. 305-324. 
[this page intentionally left blank] 